\title{
A survey on relationship between Gendarmerie Coast Guard Academy (GCGA) students' physical activity and COVID-19 infection
}

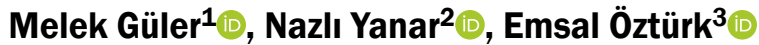 \\ ${ }^{1}$ Karamanoğlu Mehmetbey University, Sport Science Faculty, Turkey \\ ${ }^{2}$ Ankara University, Institute of Health Sciences, Turkey \\ ${ }^{3}$ Ankara Gendarmerie Coast Guard Academy, Turkey
}

\begin{abstract}
Background: The primary aim of this study was to reveal whether the Gendarmerie Coast Guard Academy (GCGA) students caught and went through the coronavirus disease 2019 (COVID-19) according to their physical activity levels during the COVID-19 pandemic process.

Materials and methods: The research group of the study consisted of 332 volunteer male students studying at the GCGA. International Physical Activity Questionnaire-Short Form (IPAQ-SF) and personal information form were used as data collection tools in the study. The data obtained from the questionnaires were analysed in the Jamovi 1.8.2 statistical software programme with a 95\% confidence interval and a 5\% margin of error. In the analysis of data, non-parametric correlation test was used for pairwise comparisons and Multinomial and Binomial Logistic Regression test was used for comparisons of subcategories.

Results: According to students' body mass index scores, $73.49 \%$ of the students were of normal weight. The results of the analysis, showed that $29.82 \%$ of the GCGA students had COVID-19, and $70.18 \%$ of them did not have COVID-19. It was determined that $91.92 \%$ of those who had COVID-19 had mild illness and recovered at home. According to the metabolic equivalence classification of students, a negative and significant relationship between students' physical activity levels (inactive < minimally active < very active) and the risk of getting the positive results for COVID-19 (yes < no) and the severity of COVID-19 (in intensive care < in the hospital < mildly at home) was found.

Conclusions: It could be said that increasing the physical activity level of students can reduce the possibility of having COVID-19 and also increase the probability of mild illness not requiring hospitalisation in those with positive COVID-19 test result.
\end{abstract}

(Int Marit Health 2021; 72, 4: 259-267)

Key words: physical activity, catching COVID-19, overcome COVID-19

\section{INTRODUCTION}

The World Health Organization declared coronavirus disease 2019 (COVID-19) as an international public health emergency on January 30, 2020 [1] and a global pandemic on March 11, 2020 [2]. For the prevention of social contact and viral spread, curfews, quarantine practices, social distance rules, closure of educational institutions, reduction of travel, and other preventive methods have been observed to reduce the number of infections and deaths caused by COVID-19 [3]. These public health measures implemented to prevent the spread of the pandemic create significant disruptions of staying physically active [4]. During the period of staying at home, sedentary behaviours around leisure interests and screen activities are exhibited [2]. According 
to the results of the studies ( $n=66$ ) included in a systematic review, it was concluded that physical activity (PA) decreased and sedentary behaviours increased during the COVID-19 pandemic [5].

When the causes of death in the world are examined, lack of PA is stated as the fourth risk factor [6]. PA is any body movement produced by skeletal muscles that results in energy expenditure above resting (basal) levels [7, 8]. In general, it includes "exercise, sports and physical activities performed as a part of daily life, occupation, leisure time and active transportation" [9]. Achieving minimum levels of PA (i.e., $150 \mathrm{~min}$ of moderate to vigorous PA, $75 \mathrm{~min}$ of vigorous PA per week, or a combination of both) and reducing sedentary behaviour during times of social isolation has become a challenge and also a must for everyone [10]. In studies, it has been reported that the total metabolic equivalence (MET)-min/week values of the participants decreased during the pandemic compared with the pre-COVID-19 pandemic [11-17]. Considering the results from an international study, it has been shown that restraint has a negative effect on PA behaviour, with a 33\% reduction in active minutes/day and a significant increase in sitting time (from 5 to $8 \mathrm{~h}$ per day) [13]. This is seen as a cause for concern, as just a few days of inactivity can lead to muscle loss, neuromuscular damage, insulin resistance, and fat accumulation [18]. Prolonged physical inactivity can cause hypertension, obesity, and heart disease [19]. At the onset of the pandemic, it was emphasized that maintaining one's PA during periods of social restrictions and quarantine is an important strategy for maintaining both physical and mental health [20, 21]. Educational approaches are changing because of the situation related to COVID-19 and perhaps university students who receive hands-on training are more affected by this situation [22]. Accordingly, it is thought that the COVID-19 epidemic caused changes in the PA level of Gendarmerie Coast Guard Academy (GCGA) students. Based on all this, the aim of this study was to investigate the relationship between the PA levels of GCGA students during the COVID-19 pandemic and the status of catching and going through COVID-19. In this context, "relationship between Gendarmerie Coast Guard Academy (GCGA) students' physical activity and COVID-19 infection" constituted the problem statement of the research. In order to answer this problem, answers to the following sub-problems were sought.

\section{MATERIALS AND METHODS RESEARCH MODEL}

The model of this research, which aimed to determine the PA levels of university students during the pandemic process, and their status of catching COVID-19 and having the illness, was the "descriptive, relational screening (survey)" cross-sectional model.

\section{RESEARCH GROUP}

Three hundred thirty-two university students studying at GCGA participated in the study voluntarily. The mean age of the students ( $20.26 \pm 5.68$ years), the mean weight $(74.80 \pm 8.09 \mathrm{~kg})$ and the mean height $(178.46 \pm 9.95 \mathrm{~cm})$ were measured. The total MET averages of the students were $4126.4 \pm 4098.1$ and the body mass index (BMI) averages were $23.53 \pm 1.92$.

\section{DATA COLLECTION TOOLS}

The data were collected by creating the International Physical Activity Questionnaire-Short Form (IPAQ-SF) questionnaire and the personal information form prepared by the researcher in the virtual environment (google-form). Questionnaires were sent online to the students who volunteered after being asked if they wanted to participate in the study. In addition, the students were asked to mark the phrase 'I voluntarily participate in the study' at the beginning of the questionnaire.

\section{COVID-19 DETECTION}

An attempt was made to contain the COVID-19 epidemic thanks to the 'HES' (Life Fits in the House) telephone application developed by the Ministry of Health in Turkey and made mandatory for every individual [23]. With the 'HES' code, the positive or negative polymerase chain reaction (PCR) test result of the individual is reflected in the application, and it is ensured that the person does not go outside during the 15-day quarantine process. In our cross-sectional study, it has been determined whether the students have had COVID-19 according to the PCR test results in the 'HES' code to this day.

\section{INTERNATIONAL PHYSICAL ACTIVITY QUESTIONNAIRE-SHORT FORM (IPAQ-SF)}

The PA level of the participants was evaluated by means of the IPAQ-SF. A reliable and valid questionnaire was designed by an Australian researcher, Michael Booth in 1996 to examine the health and PA levels of the population and the relationship between them. The International Physical Activity Assessment Group developed the IPAQ based on this survey; the Turkish validity and reliability study of the scale was conducted by Öztürk in 2005 [24]. IPAQ is designed in two forms, short and long, to detect PA and sedentary lifestyles of adults. The short form consists of seven questions; provides information on time spent walking, moderate-to-vigorous and vigorous activities. It basically includes questions about PA done for at least 10 minutes in the last 7 days. Time spent sitting is considered a separate question. Scoring of the questionnaire includes the total of walking, moderate-intensity and vigorous activity in terms of duration (min) and frequency (days) [25]. It is determined how many 


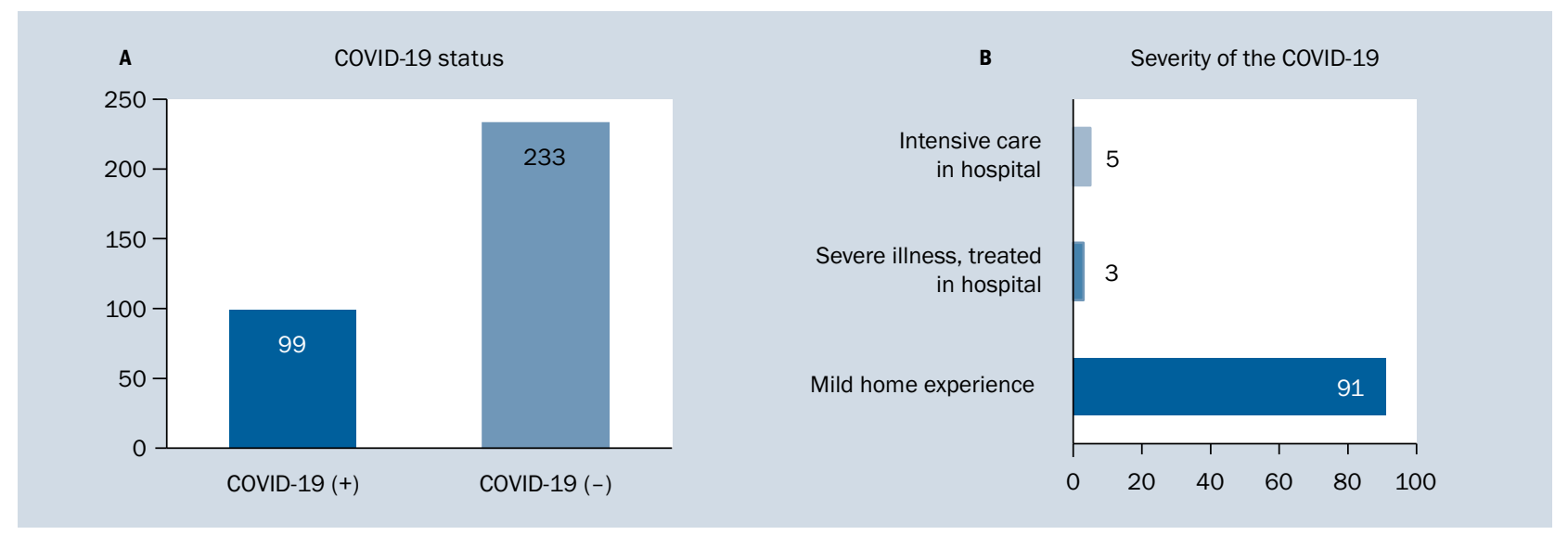

Figure 1. Coronavirus disease 2019 (COVID-19) status (A) and disease severity (B) in the participants of the study

days in the last week and for how long for each day, heavy physical activities, moderate-intensity physical activities, and walking are done. In the last question, the time spent daily without moving (sitting, lying down, etc.) is determined. As a result of these calculations, the "MET-minute" score is reached. A MET-minute is calculated by multiplying the minute of activity with the MET score.

A person at rest consumes $3.5 \mathrm{~mL}$ of oxygen per $\mathrm{kg}$ per minute. In IPAQ, it is accepted that AFA = 8.0 MET, OFA = 4.0 MET, $Y=3.3$ MET [26].

\section{MET calculation criteria:}

- Walking MET-min/week $=3.3 \times$ walking minutes $\times$ the number of walking days;

- Moderate intensity MET-min/week $=4.0 \times$ minutes of moderate-intensity activity $\times$ the number of days of moderate-intensity activity;

- Vigorous MET-min/week $=8.0 \times$ minutes of vigorous activity $\times$ the number of days of vigorous activity;

- Total, MET-min/week = $($ walking + moderate + vigorous + sitting) MET-min/week;

- Physical activity level is determined in three categories: inactive (< 600 MET-min/week) group, minimal active (> 600-3000 MET-min/week) group and very active (<3000 MET-min/week) group.

It was obtained from the Scientific Research and Publication Ethics Committee of the Karamanoğlu Mehmetbey University Rectorate on 17.08.2021 (Document no: 26301).

\section{ANALYSIS OF THE DATA}

In the study, frequency $(n)$, percentage (\%), arithmetic mean $(\mathrm{x})$ and standard deviation (SD) were used for personal information. When assessing the normality of the data distribution, it was determined that the skewness and kurtosis coefficients of the data were not between +1.5 and -1.5 . This indicates that the results obtained in the study do not show a normal distribution [27]. From this point of view, non-parametric correlation test was used in relational searches and Binomial and Multinomial Logistic Regression test was used in comparisons of subcategories.

\section{RESULTS}

The number of people who became infected with coronavirus and the distribution of patients depending on the severity of the disease are shown in Figure 1.

It was determined that $29.82 \%(n=99)$ of the participants tested positive for COVID-19, and in $70.18 \%$ $(n=233)$ the test for COVID-19 was negative. The vast majority of those with confirmed COVID-19 infection (91.92\%; $\mathrm{n}=91$ ) had mild symptoms and were treated at home, $3.03 \%(n=3)$ had severe illness requiring hospitalisation, and $5.05 \%(n=5)$ were treated in the intensive care unit Figure 2 shows the number of COVID-19 infected participants according to the MET and BMI categories.

According to Figure 2, 20.2\% ( $n=67)$ of the participants who had COVID-19 had normal weight and 9.6\% $(n=32)$ were in the overweight group. Of the participants, $53.3 \%$ $(n=177)$ of those who had not have COVID-19 were at normal weight and $16.9 \%(n=56)$ were in the overweight group. Of the participants, $0.6 \%(n=2)$ of those who had COVID-19 were inactive, $8.4 \%(n=28)$ were minimally active, and $20.8 \%(n=69)$ were in the very active group. Of the participants, $5.1 \%(n=17)$ of those who did not have COVID-19 were inactive, $24.7 \%(n=82)$ were minimally active, and $40.46 \%(n=134)$ were in the very active group. Numbers and percentages of patients with severe or mild COVID-19 according to their PA levels (MET) classification are given in Table 1.

As shown in Table 1, 2.02\% of the participants who had a mild home experience with COVID-19 were in the inactive group, $24.24 \%$ were in the minimally active group, and $65.66 \%$ were in the very active group. It is seen that $3.03 \%$ of those who had severe COVID-19 and were treated in the 


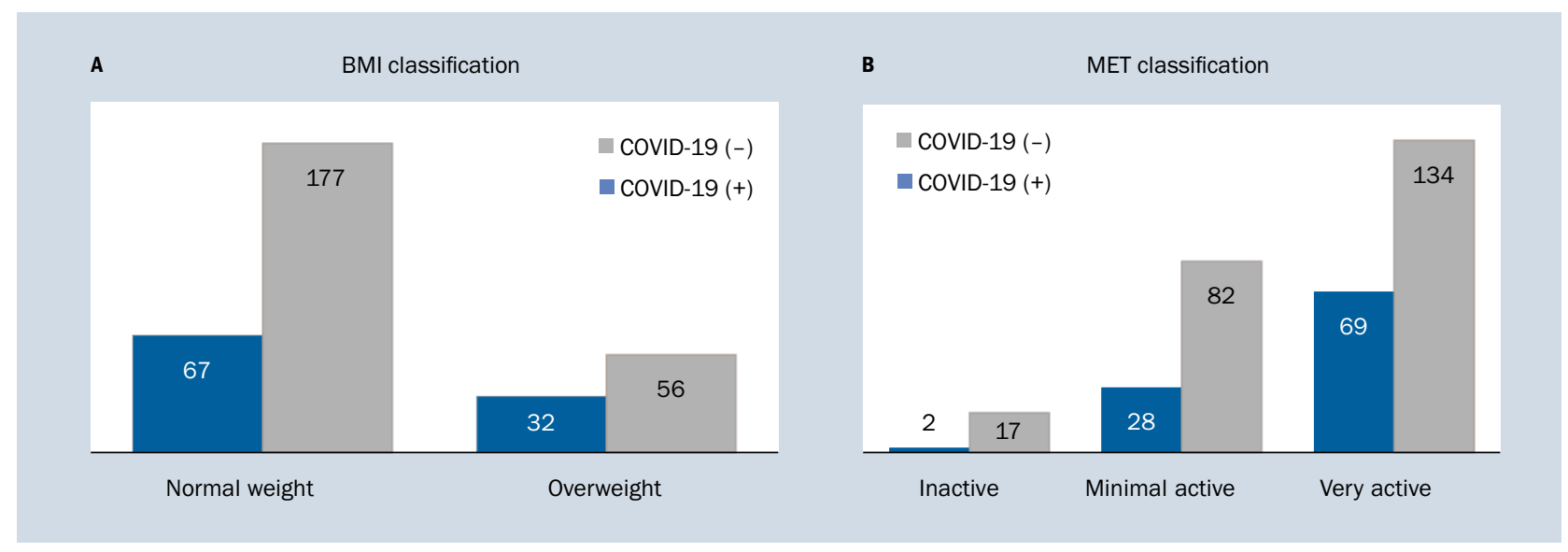

Figure 2. Body mass index (BMI) (A) and metabolic equivalent (MET) (B) in participants with or without coronavirus disease 2019 (COVID-19)

Table 1. Numbers and percentages of patients with severe or mild coronavirus disease 2019 (COVID-19) according to the metabolic equivalent (MET) classification

\begin{tabular}{|c|c|c|c|c|c|c|c|}
\hline \multirow[t]{3}{*}{ Severity of COVID-19 } & \multirow[b]{3}{*}{$\mathbf{N}$} & \multicolumn{6}{|c|}{ MET classification } \\
\hline & & \multicolumn{2}{|c|}{ Inactive } & \multicolumn{2}{|c|}{ Minimal active } & \multicolumn{2}{|c|}{ Very active } \\
\hline & & $\mathbf{F}$ & $\%$ & $\mathbf{F}$ & $\%$ & $\mathbf{F}$ & $\%$ \\
\hline Mild home experience & 99 & 2 & 2.02 & 24 & 24.24 & 65 & 65.66 \\
\hline Severe illness, treated in hospital & 99 & 0 & 0 & 3 & 3.03 & 0 & 0 \\
\hline Intensive care in hospital & 99 & 0 & 0 & 1 & 1.01 & 4 & 4.04 \\
\hline
\end{tabular}

Table 2. Correlation test results of contracting coronavirus disease 2019 (COVID-19) and the severity of the disease according to the metabolic equivalence (MET) classification of the participants

\begin{tabular}{lll}
\hline MET classification & Contracting COVID-19 & Severity of COVID-19 \\
\hline$R$ & -0.125 & -0.129 \\
$P$ & $0.023^{*}$ & $0.018^{*}$ \\
\end{tabular}

hospital, 3.03\% were in the minimal active group; $1.01 \%$ of those who were treated due to COVID-19 in the intensive care unit were in the minimal active group and $4.04 \%$ were in the very active group.

As shown in Table 2, a statistically significant, strong negative correlation was found between the MET classification of the participants and their COVID-19 status $(r=-0.125, p<0.05)$. The increase in the PA levels of the participants (inactive $<$ minimally active $<$ very active) and the rate of not getting positive results for COVID-19 (yes < no) are directly proportional. There is a statistically significant, strong negative correlation between the MET classification of the participants and their COVID-19 status $(r=-0.129$, $p<0.05)$. The increase in the PA levels of the participants (inactive $<$ minimally active very active) and the rate of mild COVID-19 treated at home (in the intensive care unit $<$ hospital < mildly at home) are directly proportional. The probability estimation between the MET classification and the categories of contracting COVID-19 is given in Table 3 with the results of the Binomial Logistic Regression test.

As presented in Table 3, the probability of contracting COVID-19 according to the MET classification model is statistically significant, and the MET classification can increase the probability of contracting COVID-19 by 8.5 times $\left(R^{2}=0.28, p<0.001\right)$. When the independent variables are examined, it is seen that being in the inactive group may increase the probability of having COVID-19 by 0.3 times compared with those in the minimally active group, but this probability is not statistically significant ( $p>0.05$ ). Being in the active group may increase the probability of having COVID-19 by 
Table 3. Binomial Logistic Regression test results of participants' metabolic equivalence (MET) classification and contracting coronavirus disease 2019 (COVID-19)

\begin{tabular}{llllll}
\hline Predictor & Estimate & SE & Cl & OR & P \\
\hline Intercept & 2.14 & 0.748 & $1.96-36.79$ & 8.5 & $0.004^{*}$ \\
Minimal active-inactive & -1.07 & 0.779 & $0.08-1.59$ & 0.3 & 0.17 \\
Very active-inactive & -1.48 & 0.762 & $0.05-1.02$ & 0.2 & 0.05 \\
$\mathrm{~N}=332, \mathrm{R}^{2}=0.28$ (Negelkerkes), Model $=\chi^{2}(2)=6.77, \mathrm{p}=0.034$ & & & & & \\
${ }^{*} \mathrm{p}<0.01 ; \mathrm{Cl}-$ confidence interval; $\mathrm{OR}-$ odds ratio; $\mathrm{SE}-$ standard error & & & &
\end{tabular}

Table 4. Multinomial Logistic Regression test results of participants' metabolic equivalence (MET) classification and having coronavirus disease 2019 (COVID-19) illness

\begin{tabular}{lllllll} 
& Predictor & Estimate & SE & CI & OR & P \\
\hline COVID-19 (-)/COVID-19 (+) & Intercept & 2.141 & 0.748 & $1.96-36.82$ & 8.5 & $0.004^{*}$ \\
& Minimal active-inactive & -0.912 & 0.783 & $0.08-1.86$ & 0.4 & 0.24 \\
& Very active-inactive & -1.417 & 0.763 & $0.05-1.08$ & 0.2 & 0.06 \\
$\mathrm{~N}=332, \mathrm{R}^{2}=0.37$ (Negelkerkes), Model $=\chi^{2}(2)=14.9, \mathrm{p}=0.021$ & & & & &
\end{tabular}

${ }^{*} \mathrm{p}<0.01 ; \mathrm{Cl}$ - confidence interval; $\mathrm{OR}$ - odds ratio; SE - standard error

0.2 times compared with those in the very active group, this probability is not statistically significant $(p>0.05)$. The probability estimate between the MET classification and the subcategories of COVID-19 status and severity is given in Table 4 with the results of the Multinomial Logistic Regression test.

As shown in Table 4, the status model of surviving COVID-19 according to the MET classification is statistically significant, and the MET classification can increase the probability of passing COVID-19 milder by 8.5 times $\left(R^{2}=0.37 p<0.001\right)$. When the independent variables are taken into consideration, it is seen that being in the minimally active group may increase the probability of having mild COVID-19 at home by 0.4 times compared with those in the inactive group, while this probability is not statistically significant $(p>0.05)$. While it is seen that being in the very active group among the participants may increase the probability of having mild COVID-19 at home by 0.2 times compared with those in the inactive group, this probability is not statistically significant ( $p>0.05)$.

\section{DISCUSSION}

The following results were obtained in the study conducted to examine the PA levels of GCGA students and the coronavirus infection rate and the severity of COVID-19. It was determined that $29.82 \%$ of the participants tested positive for COVID-19, and in $70.18 \%$ the test for COVID-19 was negative. It was determined that $91.92 \%$ of the participants had a mild COVID-19 at home, 3.03\% had severe illness and were in a hospital, and $5.05 \%$ were treated in the intensive care unit. As of May 10, 2020, more than 4 million cases of
COVID-19 and 280,000 deaths from COVID-19 have been reported [28]. In China, 59\% of 1014 COVID-19 patients had positive mass PCR results and $88 \%$ had positive computed tomography scans [29]. In more than 330 laboratory-confirmed adult COVID-19 cases in Shanghai; most patients (>90\%) had mild or moderate symptoms, and more than $90 \%$ of them have been cured and discharged [30]. In New York, $10 \%$ of individuals aged $18-45$ who tested positive for COVID-19 have been reported to require hospitalisation [31]. The mean age of 1590 COVID-19 patients in Wuhan was 48.9 years, and 686 (42.7\%) patients were female. It has been reported that $20-51 \%$ of patients have at least one comorbidity, with diabetes (10-20\%), hypertension (10-15\%), and other cardiovascular and cerebrovascular diseases (7-40\%) being the most common. It has been reported that 399 (25.1\%) of the patients had at least one comorbidity [32-34]. Among cases of COVID-19, patients with any comorbidity had worse clinical outcomes than those without. More comorbidities have also been reported to be associated with worse clinical outcomes [35]. Although patients from all age groups are infected with COVID-19, elderly patients seem to be more susceptible to infection and it is seen that the middle-aged group is the most affected. Although infection rates among children and young adults are very low, an incidence rate of $0.8-4.0 \%$ is reported [36]. Many young individuals with COVID-19 infection are said to develop a relatively mild illness and recover almost completely within 5-7 days [37]. It has been reported that generally young people have a mild course of COVID-19 and symptoms improve within a week [38]. In addition, one of the criteria that GCGA students must meet in order to be 
admitted to university is the absence of chronic disease, which could also have had an impact on the results. These research results support the results of our study.

It was determined that $71.5 \%$ of the students had normal weight, according to their BMI values, and their PA levels were as follows: $51.1 \%$ were very active and $41.6 \%$ were minimally active. Moreover, $20.8 \%$ of students who had COVID-19 and $40.46 \%$ of those who had not had COVID-19 were also in the very active group. Ain addition, $20.2 \%$ of students who have had COVID-19 and $53.3 \%$ of those who have not had COVID-19 were in the normal weight group. To prevent the spread of the COVID-19 epidemic and to reduce the number of cases, curfews were introduced on the days and times specified by the authorities, however the measures taken have contributed positively to the spread of the epidemic as reducing the amount of time spent outdoors caused changes in the daily regular PA and exercise activities of individuals [39]. In a study that included many countries (Asia [36\%], Africa [40\%], Europe [21\%]) and 1047 responses from other continents (3\%), COVID-19-related house detention has been reported to have a negative effect on all PA levels (vigorous, moderate, walking, and general) [13]. In this sample of physically active adults in Norway, during the pandemic period, the levels of PA decreased in 177 (13.8) respondents, remained unchanged in 824 (64.3) and increased in 280 (21.9) [40]. The impact of social distancing measures on general PA, an important determinant of health, should be taken into account, especially if long-term social distancing is needed [41]. It can be said that before the pandemic, military students' PA levels and participation in sports activities were generally high [42]. In an experimental study, it was determined that the body weight and BMI of military students within 6 months did not change within or between groups [43]. Gaździńska et al. (2015) [44] stated that $71.3 \%$ of the military students had normal body weight, $25.3 \%$ were overweight and $3.4 \%$ were obese, according to their BMI values. In a study conducted with the students of the Martial University, it was reported that $52 \%$ of the students performed sports activities in their spare time and $46 \%$ did physical activities besides attending physical exercise classes at school [45]. In another study conducted with military students, it was concluded that students generally had minimally active and very active MET levels [46]. In military students, the content of mainly martial arts, condition, and endurance exercises may enable students to be physically active both in and out of class. These studies support the results of our study.

It was shown that $2.02 \%$ of the participants who had a mild home experience with COVID-19 were in the inactive group, $24.24 \%$ were in the minimally active group, and $65.66 \%$ were in the very active group. It is seen that $3.03 \%$ of those who had severe COVID-19 and were treated in the hospital were in the minimal active group; $1.01 \%$ of those who were treated due to COVID-19 in the intensive care unit were in the minimal active group and $4.04 \%$ were in the very active group. In order to prevent the COVID-19 pandemic, higher education institutions in almost every country closed in the first half of 2020 [47]. In our country, the transition to distance education has been made as of 16.03.2020. These public health measures implemented to prevent the spread of the illness create an obstacle to staying physically active [4]. A decrease in PA may also cause a decrease in immune and cardiorespiratory system functions [48]. Physical activity significantly reduces the risks of common noncontagious diseases, including cardiovascular disease, diabetes, some cancers, and depression $[49,50]$. It is said that there is no evidence to suggest that physically active individuals will develop a less severe form of the disease when infected with COVID-19 [51]. In addition, it is reported to reduce the severity of symptoms [52] and the improves immune response to infections, which may affect clinical outcomes in COVID-19 patients [53]. It is well appropriate to exercise at home using a variety of safe, simple, and easily applicable exercises, to prevent the spread of coronavirus outside and to maintain fitness levels [54]. It is recommended that individuals who are in contact with COVID-19 and have a positive diagnosis but are asymptomatic should continue to do moderate-intensity regular PA at home [55]. In the study, the distance education of students during the pandemic may have reduced the rate of COVID-19 transmission by reducing their contact with other people. The students' persistence in exercise and physical activities in the house may have kept their immunity at a certain level, allowing them to have a mild period of COVID-19 at home.

A statistically significant negative high correlation was found between the students' MET levels and the status of contracting and going through COVID-19. It has been determined that the probability of having COVID-19 has increased by 0.3 times in the inactive group compared with those in the minimally active group, and the probability of having COVID-19 in the active group by 0.2 times compared with the students in the very active group, while these probabilities were not statistically significant. Although it was found that the probability of having COVID-19 mildly at home for students in the minimally active group may increase 0.4 times compared with those in the inactive group, and the probability of having COVID-19 at home for the students in the very active group is 0.2 times higher than those in the inactive group, these possibilities are not statistically significant. Prolonged physical inactivity can cause hypertension, obesity, and ischaemic heart disease [19]. For example, a 2-week reduction in daily steps from $\sim 10,000$ to $\sim 1,500$ steps lead to impaired insulin sensitivity and lipid metabolism, increased visceral fat, reduced 
lean mass, and reduced cardiovascular fitness in healthy adults [56]. Regular PA has been shown to be effective in preventing the most common noncontagious pathologies [57] and reducing the risk of death [50, 58]. Regarding contagious diseases, PA improves immune response which can reduce both the risk of SARS-CoV-2 infection and the severity of COVID-19 symptoms [59]. Therefore, it is recommended to increase the immune function with appropriate PA that will boost the body against the virus before the illness [60]. It is recommended to develop a regular exercise habit with approximately 2500 MET weekly PA during the pandemic period [61]. An acute exercise (moderate-vigorous-intensity aerobic exercise, less than $60 \mathrm{~min}$ ) strengthens the immune response of circulatory and peripheral tissues (e.g. respiratory, and intestinal epithelium) [62]. It is recommended to stay below $80 \%$ of the maximum heart rate, as stated in the "Journal of Sports Health" [63]. It has been reported that the biggest obstacle to healthy nutrition and regular exercise in military training is insufficient time [64]. Although the distance lessons or the work carried out continue during the pandemic process, in free time; since we add the hours spent on the road to and from school into the free time period, it can be said that everyone has an increase of approximately 2 hours more [65]. In the study, military students' continuance to exercise and PA during the pandemic, and that the distance courses they take are mainly condition-improving could induce to think that it may have helped the students to have COVID-19 less and to have the illness mildly or at home, even if they got positive results for COVID-19.

\section{LIMITATIONS OF THE STUDY}

The limitation of our study is whether the students had COVID-19 according to the results of PCR tests based on the application of 'HES' code only. Our study is a cross-sectional study and the COVID-19 (+) and COVID-19 (-) statuses of individuals were determined during the time period of the study.

\section{CONCLUSIONS}

The study showed that GCGA students had a high level of PA during the pandemic and continued to exercise at home. It has been determined that the rate of contracting COVID-19 in students is low and those having COVID-19 experienced a mild illness at home. The high level of PA of the students may suggest the possibility of not contracting COVID-19 and the possibility of mildly having the illness at home. The physical inactivity brought by the pandemic may have affected more, especially the universities that provide applied education. Military students have had to attend applied and sportive classes mainly remotely. However, contrary to expectations, military students tried to do sports and keep their physical activities high in their home environment. The course discipline taken by military students may have been effective in the formation of this situation. In our study, the possibilities of high PA level and contracting COVID-19 in the future were discussed. In further studies on this subject, there is a need for definite results out of possibilities. In addition, further studies can investigate which people are most susceptible to coronavirus infection. Vaccination and dose status of individuals can also be included in the evaluation and inferences can be made.

\section{Conflict of interest: None declared}

\section{REFERENCES}

1. Wang $X$, Hegde S, Son C, et al. Investigating mental health of US college students during the COVID-19 pandemic: cross-sectional survey study. J Med Internet Res. 2020; 22(9): e22817, doi: 10.2196/22817, indexed in Pubmed: 32897868.

2. World Health Organization. Regional Office for the Eastern Mediterranean. Excessive Screen Use and Gaming Considerations During \#COVID19. online: http://www.emro.who.int/mnh/news/ considerations-for-young-people-on-excessive-screen-use-during-covid19.html (accessed on 26 May 2021).

3. Nussbaumer-Streit B, Mayr V, Dobrescu Al, et al. Quarantine alone or in combination with other public health measures to control COVID-19: a rapid review. Cochrane Database Syst Rev. 2020; 9: CD013574, doi: 10.1002/14651858.CD013574.pub2, indexed in Pubmed: 33959956.

4. Woods JA, Hutchinson NT, Powers SK, et al. The COVID-19 pandemic and physical activity. Sports Med Health Sci. 2020; 2(2): 55-64, doi: 10.1016/j.smhs.2020.05.006, indexed in Pubmed: 34189484.

5. Stockwell S, Trott M, Tully M, et al. Changes in physical activity and sedentary behaviours from before to during the COVID-19 pandemic lockdown: a systematic review. BMJ Open Sport Exerc Med. 2021; 7(1): e000960, doi: 10.1136/bmjsem-2020-000960, indexed in Pubmed: 34192010.

6. Dünya Sağlık Örgütü. Fiziksel Aktiviteye İlişkin Küresel Eylem Planı 2018-2030: Daha sağlıkı bir dünya için daha aktif insanlar Retrieved Nov 2020, 24. Erişim tarihi (26.04.2021). https:// www, who,int/ncds/prevention/physical-activity/global-action-plan-2018-2030/en/.

7. Morrow JR, Jackson AW, Bazzarre TL, et al. A one-year follow-up to physical activity and health. A report of the Surgeon General. Am J Prev Med. 1999; 17(1): 24-30, doi: 10.1016/s07493797(99)00030-6, indexed in Pubmed: 10429749.

8. Caspersen CJ, Powell KE, Christenson GM. Physical activity, exercise, and physical fitness: definitions and distinctions for health-related research. Public Health Rep. 1985; 100(2): 126-131, indexed in Pubmed: 3920711.

9. Garber CE, Blissmer B, Deschenes MR, et al. Quantity and quality of exercise for developing and maintaining cardiorespiratory, musculoskeletal, and neuromotor fitness in apparently healthy adults: guidance for prescribing exercise. Med Sci Sports Exerc. 2011; 43(7): 1334-1359, doi: 10.7916/D8CR5T2R.

10. Peçanha T, Goessler KF, Roschel $H$, et al. Social isolation during the COVID-19 pandemic can increase physical inactivity and the global burden of cardiovascular disease. Am J Physiol Heart Circ 
Physiol. 2020; 318(6): H1441-H1446, doi: 10.1152/ajpheart.00268.2020, indexed in Pubmed: 32412779.

11. Srivastav AK, Sharma N, Samuel AJ. Impact of Coronavirus disease-19 (COVID-19) lockdown on physical activity and energy expenditure among physiotherapy professionals and students using web-based open E-survey sent through WhatsApp, Facebook and Instagram messengers. Clin Epidemiol Glob Health. 2021; 9: 78-84, doi: 10.1016/j.cegh.2020.07.003, indexed in Pubmed: 32838062

12. Martínez-de-Quel Ó, Suárez-Iglesias D, López-Flores M, et al. Physical activity, dietary habits and sleep quality before and during COVID-19 lockdown: A longitudinal study. Appetite. 2021; 158: 105019, doi: 10.1016/j.appet.2020.105019, indexed in Pubmed: 33161046.

13. Ammar A, Brach M, Trabelsi K, et al. Effects of COVID-19 home confinement on physical activity and eating behaviour Preliminary results of the ECLB-COVID19 international online-survey. Nutrients. 2020; 12(6): 1583, doi: 10.1101/2020.05.04.20072447.

14. Meza EIA, López AH. Physical activity in university student athletes, prior and in confinement due to pandemic associated with COVID-19. Retos: nuevas tendencias en educación física, deporte y recreación. 2021; 39: 112.

15. Fearnbach SN, Flanagan EW, Höchsmann C, et al. Factors protecting against a decline in physical activity during the COVID-19 pandemic. Med Sci Sports Exerc. 2021; 53(7): 1391-1399, doi: 10.1249/ MSS.0000000000002602, indexed in Pubmed: 33449607.

16. Rutkowska A, Kacperak K, Rutkowski S, et al. The impact of isolation due to COVID-19 on physical activity levels in adult students. Sustainability. 2021; 13(2): 446, doi: 10.3390/su13020446.

17. Chouchou F, Augustini M, Caderby T, et al. The importance of sleep and physical activity on well-being during COVID-19 lockdown: reunion island as a case study. Sleep Med. 2021; 77: 297-301, doi: 10.1016/j.sleep.2020.09.014, indexed in Pubmed: 33020037.

18. Narici M, De Vito G, Franchi M, et al. Impact of sedentarism due to the COVID-19 home confinement on neuromuscular, cardiovascular and metabolic health: Physiological and pathophysiological implications and recommendations for physical and nutritional countermeasures. Eur J Sport Sci. 2021;21(4):614-635, doi:10.1080/17461391.2020.1761076, indexed in Pubmed: 32394816.

19. Wu XY, Han LiH, Zhang JH, et al. The influence of physical activity, sedentary behavior on health-related quality of life among the general population of children and adolescents: A systematic review. PLoS One. 2017; 12(11): e0187668, doi: 10.1371/journal. pone.0187668, indexed in Pubmed: 29121640.

20. Chen P, Mao L, Nassis GP, et al. Coronavirus disease (COVID-19): The need to maintain regular physical activity while taking precautions. J Sport Health Sci. 2020; 9(2): 103-104, doi: 10.1016/j. jshs.2020.02.001, indexed in Pubmed: 32099716.

21. Dwyer MJ, Pasini M, De Dominicis S, et al. Physical activity: benefits and challenges during the COVID-19 pandemic. Scand J Med Sci Sports. 2020; 30(7): 1291-1294, doi: 10.1111/sms.13710, indexed in Pubmed: 32542719.

22. Inoue K, Seksenbayev N, Moldagaliyev T, et al. Changes in university classes as COVID-19 continues and new findings regarding future university instruction methods: from the perspective of Japan and Semey, Republic of Kazakhstan. Int Marit Health. 2020; 71(4): 297, doi: 10.5603/IMH.2020.0051, indexed in Pubmed: 33394497.

23. Cangil S. The HES-code and the data protection during COVID-19 pandemic in Turkey. Bioethica. 2021; 7(2): 69-74, doi: 10.12681/ bioeth. 28163.

24. Öztürk M. A research on reliability and validity of international physical activity questionnaire and determination of physical activity level in university students. Hacettepe University Health Science Institute an Unpublished PhD Thesis, Ankara (in Turkish). 2005.

25. Saglam M, Arikan H, Savci S, et al. International physical activity questionnaire: reliability and validity of the Turkish version. Percept Mot Skills. 2010; 111(1): 278-284, doi: 10.2466/06.08. PMS.111.4.278-284, indexed in Pubmed: 21058606.

26. Bozkuş T, Türkmen M, Kul M, et al. Beden eğitimi ve spor Yüksekokulu'nda öğrenim gören öğrencilerin fiziksel aktivite düzeyleri ile sağlikli yaşam biçimi davranişlarinin belirlenmesi ve ilişkilendirilmesi. Int J Sport Culture Sci. 2013; 1(3): 49-65.

27. Tabachnick BG, Fidell LS. Çok değişkenli istatistik kullanimi. Uluslararasi baski. 2013.

28. Dong E, Du H, Gardner L. An interactive web-based dashboard to track COVID-19 in real time. Lancet Infect Dis. 2020; 20(5): 533-534, doi: 10.1016/S1473-3099(20)30120-1, indexed in Pubmed: 32087114.

29. Ai T, Yang Z, Hou H, et al. Correlation of chest CT and RT-PCR testing for coronavirus disease 2019 (COVID-19) in china: a report of 1014 cases. Radiology. 2020; 296(2): E32-E40, doi: 10.1148/ radiol.2020200642, indexed in Pubmed: 32101510.

30. Ai JW, Zhang Yi, Zhang HC, et al. Era of molecular diagnosis for pathogen identification of unexplained pneumonia, lessons to be learned. Emerg Microbes Infect. 2020; 9(1): 597-600, doi: 10.1080/22221751.2020.1738905, indexed in Pubmed: 32174267.

31. New York City Department of Health and Mental Hygiene. Coronavirus disease 2019 (COVID-19) Daily Data Summary. https://www1. nyc.gov/assets/doh/downloads/pdf/imm/covid-19-daily-data-summary.pdf (Accessed March 30, 2020).

32. Huang $\mathrm{C}$, Wang $\mathrm{Y}$, Li X, et al. Clinical features of patients infected with 2019 novel coronavirus in Wuhan, China. Lancet. 2020; 395(10223): 497-506, doi: 10.1016/S0140-6736(20)30183-5, indexed in Pubmed: 31986264.

33. Chen N, Zhou M, Dong X, et al. Epidemiological and clinical characteristics of 99 cases of 2019 novel coronavirus pneumonia in Wuhan, China: a descriptive study. Lancet. 2020; 395(10223): 507-513, doi: 10.1016/S0140-6736(20)30211-7, indexed in Pubmed: 32007143.

34. Liu K, Fang YY, Deng Y, et al. Clinical characteristics of novel coronavirus cases in tertiary hospitals in Hubei Province. Chin Med J (Engl). 2020; 133(9): 1025-1031, doi: 10.1097/ CM9.0000000000000744, indexed in Pubmed: 32044814.

35. Guan WJ, Liang WH, Zhao Yi, et al. Comorbidity and its impact on 1590 patients with COVID-19 in China: a nationwide analysis. Eur Respir J. 2020; 55(5), doi: 10.1183/13993003.00547-2020, indexed in Pubmed: 32217650.

36. Bulut C, Kato Y. Epidemiology of COVID-19. Turk J Med Sci. 2020; 50(SI-1): 563-570, doi: 10.3906/sag-2004-172, indexed in Pubmed: 32299206.

37. Hull JH, Loosemore M, Schwellnus M. Respiratory health in athletes: facing the COVID-19 challenge. Lancet Respir Med. 2020; 8(6): 557-558, doi: 10.1016/S2213-2600(20)30175-2, indexed in Pubmed: 32277869.

38. Ludvigsson JF. Systematic review of COVID-19 in children shows milder cases and a better prognosis than adults. Acta Paediatr. 2020; 109(6): 1088-1095, doi: 10.1111/apa.15270, indexed in Pubmed: 32202343.

39. Chen P, Mao L, Nassis GP, et al. Coronavirus disease (COVID-19): The need to maintain regular physical activity while taking precautions. J Sport Health Sci. 2020; 9(2): 103-104, doi: 10.1016/j. jshs.2020.02.001, indexed in Pubmed: 32099716. 
40. Ernstsen L, Havnen A. Mental health and sleep disturbances in physically active adults during the COVID-19 lockdown in Norway: does change in physical activity level matter? Sleep Med. 2021; 77: 309-312, doi: 10.1016/j.sleep.2020.08.030, indexed in Pubmed: 32951994.

41. Tison GH, Avram R, Kuhar P, et al. Worldwide effect of COVID-19 on physical activity: a descriptive study. Ann Intern Med. 2020; 173(9): 767-770, doi: 10.7326/M20-2665, indexed in Pubmed: 32598162.

42. Marques A, Diniz J, da Co. Practice Of Physical Activities Among Students From Portuguese Military Schools. Proceedings Book. 2008; 838.

43. Crombie AP, Funderburk LK, Smith TJ, et al. Effects of modified foodservice practices in military dining facilities on ad libitum nutritional intake of US army soldiers. J Acad Nutr Diet. 2013; 113(7): 920-927, doi: 10.1016/j.jand.2013.01.005, indexed in Pubmed: 23419999.

44. Gaździńska A, Jagielski P, Baran P, et al. Evaluation of nutritional status and the level of physical fitness of military flying personnel staying at the training camp. Pol J Aviat Med Psychol. 2020; 24(3): 12-18, doi: 10.13174/pjambp.11.02.2020.02.

45. Juříková J. Eating Habits And Sports Activities In The Military University Students. In 7th International Scientific Conference On Kinesiology 2014; 90. https://repozitorij.kif.unizg.hr/islandora/ object/kif:1058/datastream/FILEO/view\#page=93.

46. Liguori G, Schuna JM, Tucker J, et al. Impact of prescribed exercise on physical activity compensation in young adults. J Strength Cond Res. 2017; 31(2): 503-508, doi: 10.1519/JSC.0000000000001516, indexed in Pubmed: 27253838.

47. Lopman B, Liu C, Guillou A, et al. A model of CoVID-19 transmission and control on university campuses. medRxiv. 2020, doi: 10.1101/2020.06.23.20138677.

48. Suzuki K. Chronic inflammation as an immunological abnormality and effectiveness of exercise. Biomolecules. 2019; 9(6): 223, doi: 10.3390/biom9060223, indexed in Pubmed: 31181700.

49. Warburton DER, Bredin SSD. Health benefits of physical activity: a systematic review of current systematic reviews. Curr Opin Cardiol. 2017; 32(5): 541-556, doi: 10.1097/HC0.0000000000000437, indexed in Pubmed: 28708630.

50. Ekelund U, Tarp J, Steene-Johannessen J, et al. Dose-response associations between accelerometry measured physical activity and sedentary time and all cause mortality: systematic review and harmonised meta-analysis. BMJ. 2019; 366: 14570, doi: 10.1136/ bmj.14570, indexed in Pubmed: 31434697.

51. Kaux JF, Francaux M. [Physical activity during the Covid-19 pandemic]. Sci Sports. 2020; 35(3): 117-118, doi: 10.1016/j. scispo.2020.05.001, indexed in Pubmed: 32454558.

52. Zhou F, Yu T, Du R, et al. Clinical course and risk factors for mortality of adult inpatients with COVID-19 in Wuhan, China: a retrospective cohort study. Lancet. 2020; 395(10229): 1054-1062, doi: 10.1016/ S0140-6736(20)30566-3, indexed in Pubmed: 32171076.

53. Campbell JP, Turner JE. Debunking the myth of exercise-induced immune suppression: redefining the impact of exercise on immuno- logical health across the lifespan. Front Immunol. 2018; 9: 648, doi: 10.3389/fimmu.2018.00648, indexed in Pubmed: 29713319.

54. Suzuki K. Chronic inflammation as an immunological abnormality and effectiveness of exercise. Biomolecules. 2019; 9(6): 223, doi: 10.3390/biom9060223, indexed in Pubmed: 31181700.

55. de Oliveira Neto L, de Oliveira Tavares VD, Schuch FB, et al. Coronavirus pandemic (SARS-COV-2): pre-exercise screening questionnaire (PESQ) for telepresential exercise. Front Public Health. 2020; 8: 146, doi: 10.3389/fpubh.2020.00146, indexed in Pubmed: 32373571.

56. Krogh-Madsen R, Thyfault JP, Broholm C, et al. A 2-wk reduction of ambulatory activity attenuates peripheral insulin sensitivity. J Appl Physiol (1985). 2010; 108(5): 1034-1040, doi: 10.1152/japplphysiol.00977.2009, indexed in Pubmed: 20044474.

57. Marques A, Santos T, Martins J, et al. The association between physical activity and chronic diseases in European adults. Eur J Sport Sci. 2018; 18(1): 140-149, doi: 10.1080/17461391.2017.1400109, indexed in Pubmed: 29134857.

58. Hansen BH, Dalene KE, Ekelund U, et al. Step by step: Association of device-measured daily steps with all-cause mortality-A prospective cohort Study. Scand J Med Sci Sports. 2020; 30(9): 1705-1711, doi: 10.1111/sms.13726, indexed in Pubmed: 32427398.

59. Zhou F, Yu T, Du R, et al. Clinical course and risk factors for mortality of adult inpatients with COVID-19 in Wuhan, China: a retrospective cohort study. Lancet. 2020; 395(10229): 1054-1062, doi: 10.1016/S0140-6736(20)30566-3, indexed in Pubmed: 32171076.

60. Rahmati-Ahmadabad S, Hosseini F. Exercise against SARS-CoV-2 (COVID-19): Does workout intensity matter? (A mini review of some indirect evidence related to obesity). Obes Med. 2020; 19: 100245, doi: 10.1016/j.obmed.2020.100245, indexed in Pubmed: 32342019.

61. Zhang $\mathrm{Y}$, Zhang $\mathrm{H}, \mathrm{Ma} \mathrm{X}$, et al. Mental health problems during the COVID-19 pandemics and the mitigation effects of exercise: a longitudinal study of college students in China. Int J Environ Res Public Health. 2020; 17(10), doi: 10.3390/ijerph17103722, indexed in Pubmed: 32466163.

62. Nieman DC, Wentz LM. The compelling link between physical activity and the body's defense system. J Sport Health Sci. 2019; 8(3): 201-217, doi: 10.1016/j.jshs.2018.09.009, indexed in Pubmed: 31193280.

63. ToresdahI BG, Asif IM. Coronavirus disease 2019 (COVID-19): considerations for the competitive athlete. Sports Health. 2020; 12(3): 221-224, doi: 10.1177/1941738120918876, indexed in Pubmed: 32250193.

64. Sigrist LD, Anderson JE, Auld GW. Senior military officers' educational concerns, motivators and barriers for healthful eating and regular exercise. Mil Med. 2005; 170(10): 841-845, doi: 10.7205/milmed.170.10.841, indexed in Pubmed: 16435755.

65. Karagün E. Tarvmatik Yaşanti Covid-19 Sürecinde Ruh Sağliğin Korunmasi ve Egzersiz Desteği. Spor bilimlerinde Güncel Konular ve Araştirmalar-2. 2020. Çizgi Kitabevi, Haziran, 6-34. 